\title{
FLOW VISUALIZATION OVER AN AIRFOIL WITH FLIGHT CONTROL SURFACES IN A WATER TUNNEL
}

\author{
DANiel FilipiaK*, Robert SzCZePaniaK*, TOMASz Zahorski*, Robert Bąel*, \\ Sebastian Stabryn*, Wit StrycZnIEWICZ ${ }^{* *}$ \\ * Faculty of Aviation, Polish Air Force Academy, Dywizjonu 303, 08-521 Dęblin \\ ** Department of Aerodynamics, Centre for New Technologies, Institute of Aviation, \\ al. Krakowska 110/114, 02-256 Warsaw \\ d.filipaiak1894@wsosp.edu.pl, r.szczepaniak@wsosp.pl, t.zahorski@wsosp.pl, r.babel@wsosop.pl, \\ s.stabryn@wsosp.pl,wit.stryczniewicz@ilot.edu.pl
}

\begin{abstract}
This paper demonstrates the feasibility of using-a water tunnel for the visualisation of flow in airfoils with flight control systems in the form of slots and flaps. Furthermore, the issue of using water tunnels for scientific and training purposes was explained. The technology of 3D printed models for practical tests in a water tunnel was also presented. The experiment included conducting flow visualisation tests for three airfoil models: with the Clark Y $11.7 \%$ as the base airfoil and the same airfoil with a slot and a flap. Moreover, a modification to dye injection system was introduced. The presented results of flow visualisation around models with the use of dye, confirmed the effectiveness of the applied methodology. The results and conclusions may be utilized to verify most flow-related issues in hydrodynamic tunnels and can also be used as a training element.
\end{abstract}

Keywords: water tunnel testing, airfoil, flaps, slots.

\section{INTRODUCTION}

Water tunnels play a very important role in the engineering of aerial, water and land vehicles in terms of optimizing the streamlines of designed structures. They provide much information regarding the complex processes of the fluid flow phenomenon in direct vicinity of the studied model. Over the years, water tunnels were transformed from small, simple measuring devices to advanced ones. Hydrodynamic tunnels enable time and cost efficient visualisation and interpretation of complicated fluid flow around single components and full models of designed devices. It is crucial in developing the concept of flow control and translates into more effective structures. Hydrodynamic research devices (e.g. water tunnels, model basins used for designing sailing vessels) for many years have been providing valuable information in the scope of bi- and tri-dimensional fluid mechanics of aerodynamic models operating at low flow velocities. Ludwig Prandtl was the pioneer in using research devices of such type for solving basic research dilemmas of aerodynamics. These devices are still successfully used for conducting research regarding, inter alia, issues of aerodynamics.

The development of high-manoeuvre aircraft, which fly at over-critical angles of attack and utilize the phenomenon of sub-wing vortex generated leading edge extension, resulted in an increased 
interest in hydrodynamic tunnels as diagnostic tools. Many scientist successfully demonstrated the use of hydrodynamic research devices for tri-dimensional visualisations of vortex fields formed on advanced combat aircraft with a high wing sweep, when they are in not typical positions (very high angles of attack, slide). The results of similar tests carried out in aerodynamic tunnels and practical in-flight tests correlating with the data they obtained, led to the popularisation of using relatively simple water tunnels for experiments with models, complex in terms of aerodynamics and hydrodynamics. Generally speaking, the universality of hydrodynamic research devices increased proportionally to the development of technologies associated with aviation, water and land vehicles. As a consequence, they became an important element in the engineering process, enabling insight into complex mechanisms of vortex flows [1].

\section{HISTORY OF FLOW VISUALISATION IN WATER TUNNELS}

The issue of flow visualisation in water has been known to people for a long time. It was Aristotle who elaborated on his observations of vortices, formed on open waters, which, at that time, posed a serious threat to ships passing near them. The earliest descriptions of water flow known to us, bearing the hallmarks of scientific documentation, fall in the 15 th century and they are the notes and drawings of Leonardo da Vinci, shown in fig. 1. The multi-talented da Vinci, also identified the analogy of fluid motion in water and air. He thought he had created the first water tunnel with the possibility to visualise flow. He understood the imperfection of air flow simulation with the use of water, resulting from the phenomenon of compressibility.

A century later, in his work entitled Philosophiae Naturalis Principia Mathematica, Isaac Newton came forward with the first theory regarding air resistance based on mechanics. A very important fact was that Isaac Newton spoke generally about fluids and argued that his law could be successfully applied, not only in relation to air but also to water. He believed that resistance forces in different media are proportional and correspond to density. It allowed to utilize the results of the tests performed in water for the motion in the air and, analogously, vice versa [2].

Sporadic experiments with the use of water as a medium were continued in the 19th century. In 1839, Gotthilf Heinrich Ludwig Hagen conducted research, focusing on water flowing through narrow tubes. He observed the transition of the water stream from laminar flow to turbulent flow [1]. In 1883, Osborne Reynolds proved that the transition from laminar flow to turbulent flow occurs when a specific parameter, called the Reynolds number after his name, exceeds a certain value. He obtained the results on a device presented in fig. 1a) and he documented the flow visualisation in the form of sketches.

a)

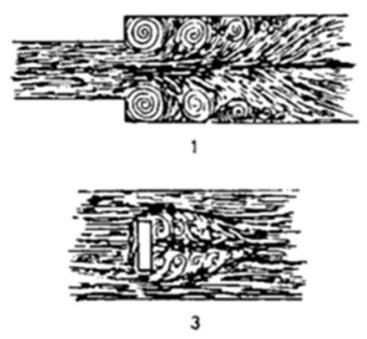

b)
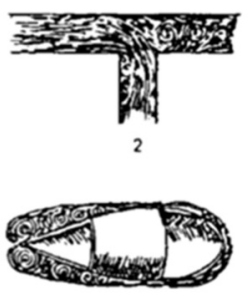

4

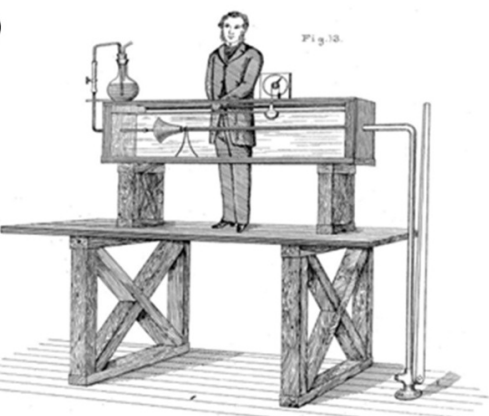

Fig. 1. a). Flow sketches made by Leonardo da Vinci: 1) Presents vortex appearing as a result of increasing flow section, 2) Flow in a diverging duct, 3) Streamline of a flat plate, 4) Streamline of a droplet-shaped profile [3]; b) The device created by $\mathrm{O}$. Reynolds for studying the conditions a water stream's transition from laminar flow to turbulent flow [4] 
The pioneer in using hydrodynamic research devices as tools for studying a number of essential issues of aerodynamics and hydrodynamics was the already mentioned German physicist, Ludwig Prandtl. He conducted experiments with bi-dimensional shapes placed in a water channel and used aluminium powder for the visualisation of flow (fig. $2 b$ ).

This method was documented by him for the first time in the publication "On Fluid Motions With Very Small Friction" in 1904. In 1934, together with O. G. Tietjens, he published "Applied Hydro and Aeromechanics" which described research on, i.a., the propagation of turbulence in boundary layers, the creation of vortices beyond a stationary and moving cylinder, the creation of periodic vortex structures beyond a cylinder, laminar and turbulent boundary layers, the creation of vortices generated by airfoil and the phenomenon of cavitation. The innovative visualisation method he used, allowed to achieve very accurate, at that time, results [5]. The experiments with a cylinder were of particular importance. In 1911, Karl Hiemenz, who was Prandtl's student, built a water tunnel especially for observing flows of that type. He observed a specific path forming behind the cylinder, created from alternately arrange vortices. At the beginning, it was believed that it is caused by the model - channel layout itself, but, after more thorough studies, the results were still repetitive. Theodore von Kármán became interested in the phenomenon. He calculated the stability of such type of vortices, which are commonly known today as Karman's vortex streets.
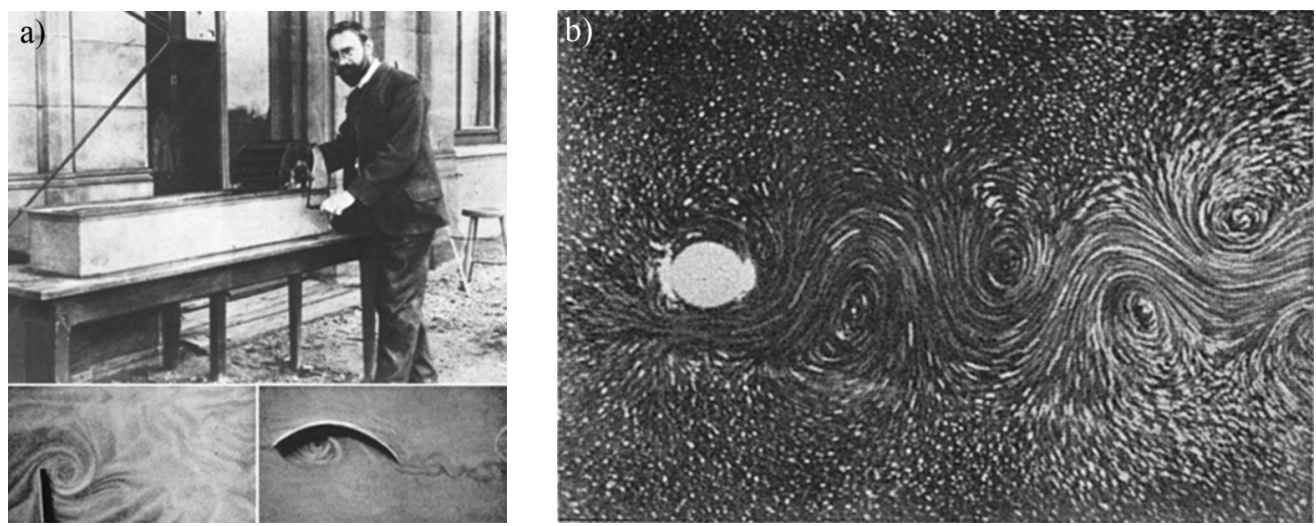

Fig. 2. a). Ludwig Prandtl's water channel used for the visualisation of the phenomenon of streams peeling off and flow images obtained with its help [5], b). The image of vortices produced behind a cylinder, obtained by Ludwig Prandtl [6].

The efforts of Prandtl and his associates confirmed that, under certain conditions, the characteristics of flow near a given object are similar for air, water or other fluids and gases. On that basis, Prandtl demonstrated that the fluid dynamics characteristics for a body exposed to flow in a given medium can be forecast on the basis of experiments in another media. His experiments found their practical application in the construction and development of military and civil aircraft. Aircraft wings were tested in water tunnels. Bear in mind the fact that using water as a substitute medium for testing flow, gives more precise results if we relate them to the flow in other non-compressible fluids, and in the case of air, to a flow with a low Mach number.

In 1910-1935, most of the studies regarding aerodynamic issues performed with the use of hydrodynamic research devices was of bi-dimensional nature and focused mainly on the behaviour of the boundary layer and the characteristics of peeling-off of the boundary layer in airfoils used in contemporary aircraft. The KWI (Kaiser Wilhelm Institute) in Göttingen, where Ludwig Prandtl worked, was the leading facility in this field. Also, hydrodynamic research devices were used more and more often for experiments associated with the phenomenon of cavitation and resistance of ships and submarines [7]. 
In the years 1935-1950 the use of hydrodynamic devices for the engineering of air and water vessels increased dramatically, mainly due to the outbreak of World War II and the consequent military demand for new technologies. Test benches at KWI in Göttingen were used during the war by the German aviation industry to improve propeller and jet aircraft designs. The performed tests were aimed at developing shapes effective at high velocities and using the cavitation phenomenon. The basis of these experiments was the assumption that the flow of gases at near supersonic velocities bears certain similarities to the flow of fluids at cavitation. The achieved results provided an approximation of the desired aerodynamic shapes, of which the main purpose was to delay the formation of a local supersonic flow in aircraft. An example of a practical application of the results of these studies is the modification of a jet aircraft Messerschmitt Me 262 Schwalbe (engine nacelles, transition between the hull and the wings). The Allies also used hydrodynamic studies in order to improve the flying and sailing vessels during World War II. The particularly renown facilities, equipped with devices of such type were the National Physical Laboratory (NPL) and the Admiralty Research Laboratory (ARL) in England, the California Institute of Technology (CalTech), the National Advisory Committee for Aeronautics (NACA) and the David Taylor Model Basin (DTMS) in the United States.

Jet aircraft appeared by the end of World War II. It translated into emphasis on high speed tests, which was highly problematic in the case of hydrodynamic devices, due to a significant gap in the Reynolds number and the phenomenon of compressibility. Increasing the flow velocity in water tunnels and channels resulted in the occurrence of an undesired phenomenon of cavitation, limiting the said velocity to such, where the flow model, more or less reflected the actual flow around a given shape in flight conditions. In order to delay the formation of cavitation, the pressure in confined tunnels was increased but, at the same time, the degree of complexity of the device itself and its cost increased. As a result, it can be concluded that using hydrodynamic water devices as tools assisting in the aircraft engineering process was associated with certain restrictions.

After the Second World War, the works of German and American scientists led to the introduction of swept wings as a mean to delay the supersonic flow. Many studies tried to understand the phenomena occurring around swept wings more accurately and flow visualisation played an important role in them. The main facilities used for experiments of such type were, among others, the National Physical Laboratory (NPL) in England and the Office National d'Etudes et de Recherches Aerospatiales (ONERA) in France, where a pump powered horizontal water tunnel and a gravitational water tunnel, respectively, could be found. The experiments during the design stage of the supersonic aircraft, the Concorde, were performed in them. At ONERA, the researchers managed to obtain very similar results of studies regarding vortex flows in aircraft with delta wings, conducted in a water and aerodynamic tunnel and in flight. It showed that, in particular cases, water tunnels can be used as a diagnostic tool, despite the large difference in the Reynolds number.

The issue of aerodynamic wake appeared together with the development of large passenger and transport aircraft, which was a significant threat to smaller aircraft. In order to thoroughly study this phenomenon, test in model tunnels were conducted.

A significant increase in the use of hydrodynamic research devices for vehicle engineering processes was noted in the 1970s. It resulted, interalia, from the need for advanced missiles and fighters, which could be capable of a controlled flight in extreme positions. 3D visualisations in-flight and in aerodynamic tunnels of vortex flows occurring in machines of such type, were not accurate enough, so people leaned towards using water tunnels for that purpose. An American company, Northrop Corporation, was the leader in their use. Almost all fighter aircraft produced in the United States at that time were tested in the Northrop tunnel. The interest in the mechanics of a helicopter rotor also increased, which could be noted in the studies performed at ONERA, where a special water tunnel was adapted to studying vortices formed at the top surface of the oscillating profile. The impact of land proximity on aircraft was also tested in water tunnels. 
Hydrodynamic research devices found its worldwide recognition as valuable diagnostic tools, supporting the engineering process. Currently, they are widely used during research on vehicles of almost every category. Due to a unique feature of visualising a $3 \mathrm{D}$ vortex flow around aerodynamically and hydrodynamically complex shapes, they were, are and will certainly be for a long time used by researchers of phenomena in the field of fluid mechanics and aerodynamics.

\section{WATER TUNNEL FLOW VISUALISATION METHODS}

\subsection{Dye visualisation}

This method is based on the emission of a dye into water via different means, so that it ends up in the field of current being the object of interest, hence, showing the structure of the flow itself (fig. 3). Most often, it is achieved through openings in a studies model, located at crucial points or tubes, which are in front of the tested object. The models themselves are most commonly white, so that they contract with the dye well. Common, diluted food colourings or water ink are very often used for this type of flow visualisation.

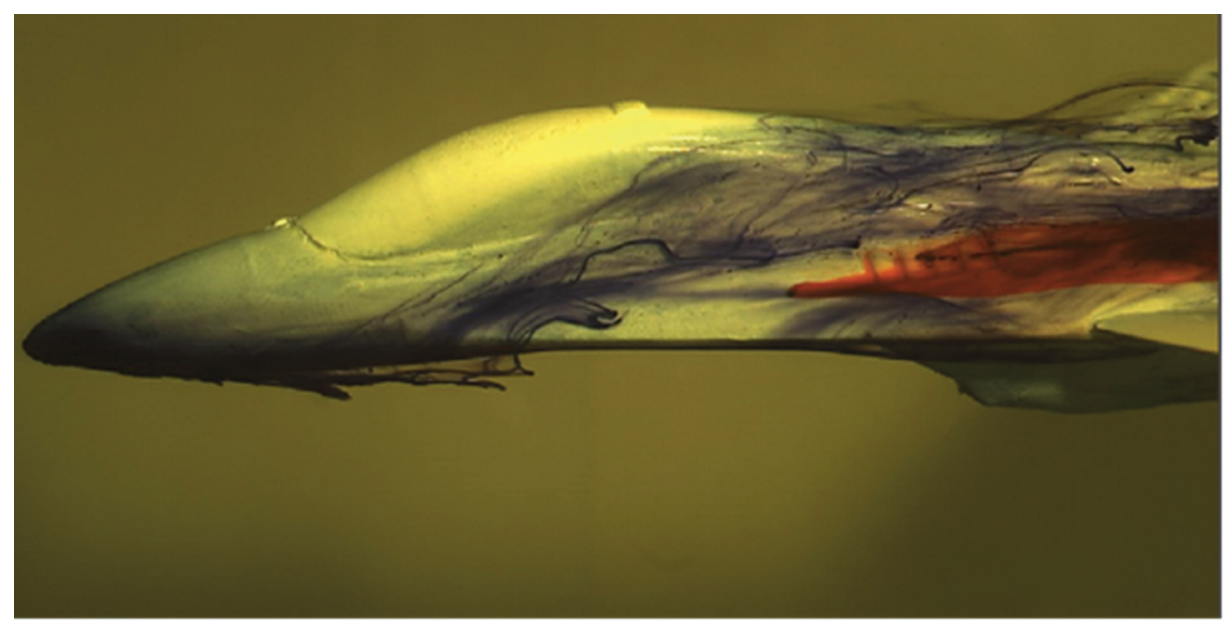

Fig. 3. Dye flow around an aircraft model [Szczepaniak, 2015]

\subsection{Laser visualisation}

This method allows observation of individual flow structure sections. Laser is the light source. A cylindrical lens converts a ray of light into a flat beam, which is placed in a plane being the object of interest. A marking agent is injected into water, which, when illuminated with a laser, is great for showing the behaviour of water streams in a given flow section. Changing laser position enables observation of other bi-dimensional areas of the current field. Two marking agents are used most often in this technique. The first one is the fluorescein sodium salt (fig. 4B), a fluorescent dye showing a strong, yellow-greenish colour when highlighted with UV light. It is easily dissolved in water and put into water as normal dyes. The second agent used with a laser is aluminium powder, dissolved as evenly as possible in water in a water tunnel tank. A laser emitting visible light is used in this case. Individual aluminium particles (fig. 4a) reflect light, which gives a trail effect on the final image, when recorded in the form of a photo or a video. Their length depends on the local flow velocity and the exposure time of the recording device. The shape of approximated streams corresponds the water streams moving in the plane of incident light. Aluminium powder is not neutrally buoyant and cannot 
flow directly with the flow of water. The results obtained from quality tests with the use of aluminium powder are identical to the results of tests with a fluorescent dye, because the powder particles disperse in water, enabling visualisation of the entire flow in the form of bi-dimensional sections, and in the case of using dyes, flow may only be observed at points with only the dye present. On the other hand, using dyes enables observation of specific phenomena, such as vortices, with greater accuracy [9].
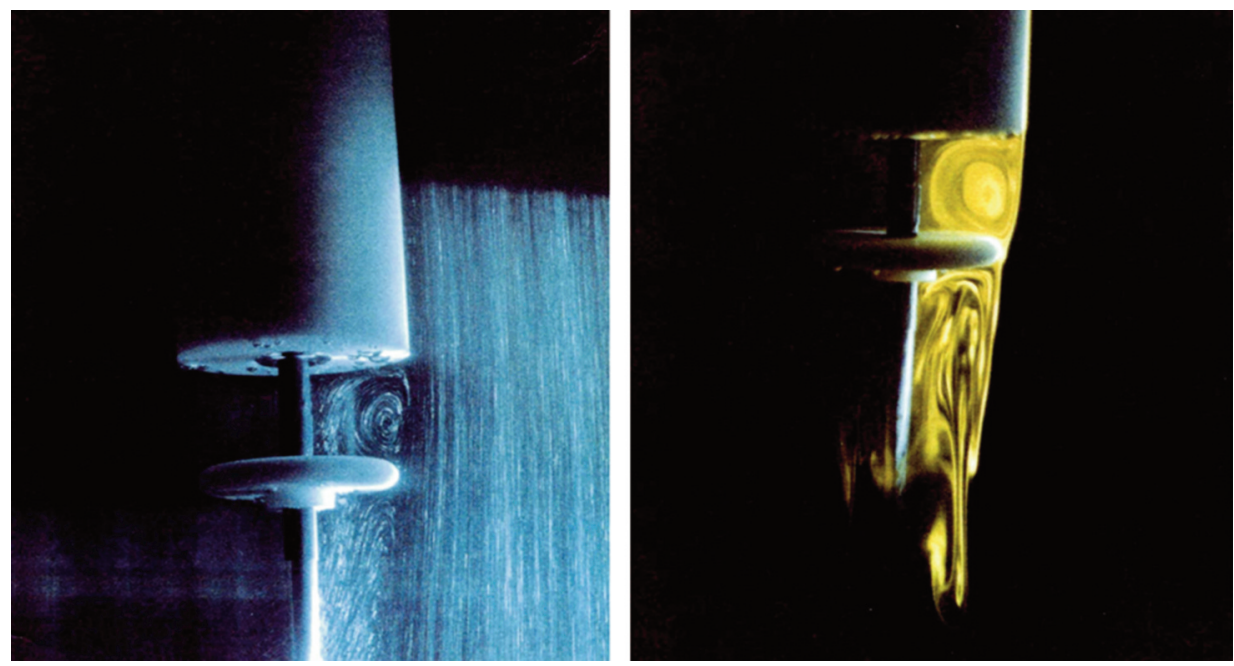

Fig. 4. Aluminium and fluorescein sodium salt as marking agents [9]

\subsection{Particle Image Velocimetry}

Particle Image Velocimetry (PIV) is one of the optical techniques of non-contact measurement. Flow analysis with the use of this method is performed by introducing seeding particles into the medium, in which the studies are conducted. Solid particles (e.g. Polyamide), sized in the order of several to a few dozen micrometers are used in case of fluids (e.g. in water tunnels). These particles are iluminated by a laser in order to record their motion with a camera or a system of many cameras. The acquired images are subjected to correlation analysis [10], with its results enabling the creation of a bi-dimensional or volumetric velocity field of the tested flow, which is a basis to determine the particle movement [9].
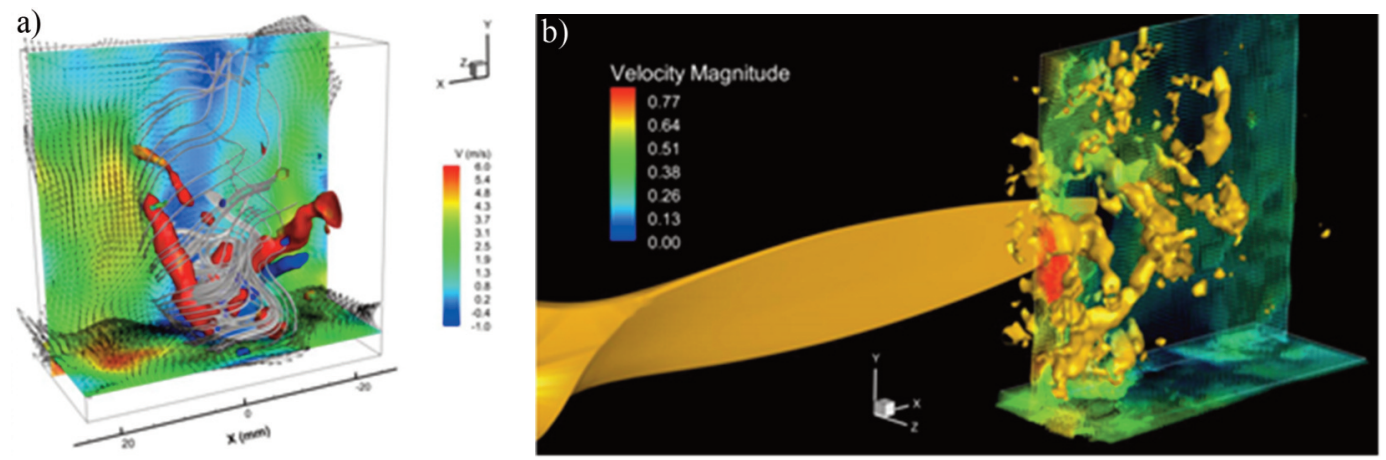

Fig. 5.a) Image of vertical vortices' turbulence running from the centre of the flame from the burner [11],

b) Volumetric velocity field showing the region of the propeller tip [12] 
An expansion of the PIV is V3V ${ }^{\mathrm{TM}}$ (Volumetric 3 - Component Velocimetry). It differs from PIV in the way of recording the motion of seeding particles. Pictures are taken by a special camera with a triple aperture. The acquired data are later analysed with the help of a specialized computer software. The position of individual particles at the time of measurement is determined, with an accuracy of up to 20 microns in the $\mathrm{X}$ and $\mathrm{Y}$ axes and up to 80 microns in the $\mathrm{Z}$ axis of the area subject to testing. It enables the determination of velocity vectors' components in 3 dimensions, which, subsequently allows to create a 3D velocity field (fig. 5) and to illustrate it, e.g., in the form of a 3D animation.

\section{EXPERIMENTAL TESTS}

\subsection{Experimtal setup}

A water tunnel, which was used for practical tests - and is a prototype - is located at the Polish Air Force Academy (fig. 6). It is used to perform experiments associated with laminar and turbulent liquid flow around different wing profiles, aircraft models and geometric figures. Consists of:

- the hydraulic part, designed to create a constant, laminar water stream with a specified flow;

- the measurement part, consisting of a mobile arm and its drives, responsible for controlling the tilt and deflection of a model;

- the part with the generator of multicoloured jets to visualise flows;

- the auxiliary part, which includes the water filtration system, image recording camera and a computer together with specialized software.

a)

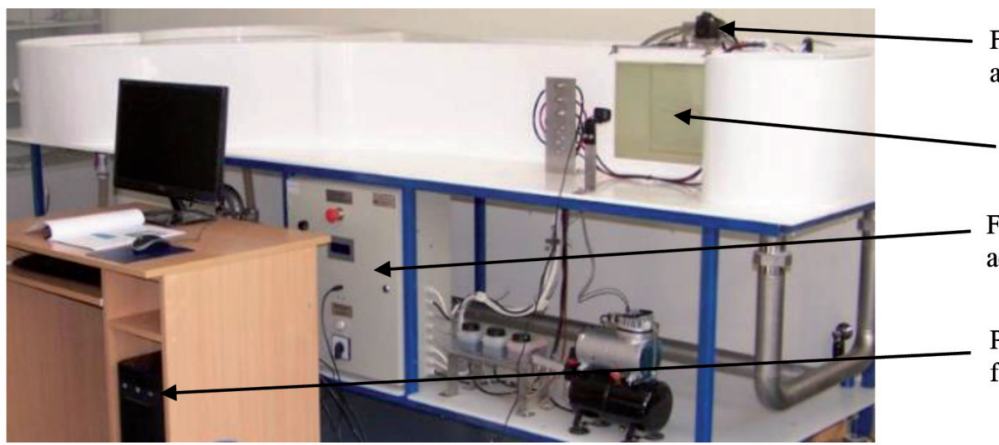

Fastening of a model with adjustable tilt and deflection angle

Measuring area

Flow velocity ang angle adiusting controllers

PC with a software adjusting the flow velocity and angles

b)

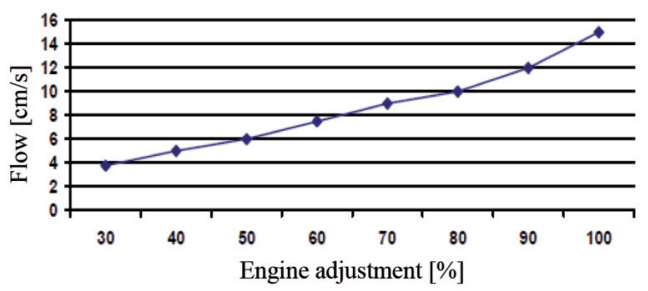

c)
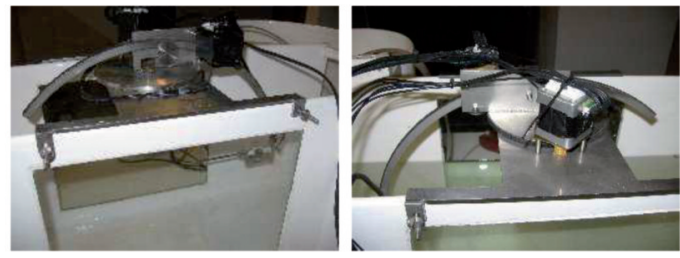

Fig. 6. Photo of a test bench for the flow visualisation of a selected medium around an observed model a) view of the entire bench [Szczepaniak, 2016], b) controlling flow velocity via engine adjustment [14], c) view of the fastening system for models inside the measurement system [14]

The water tunnel applicability scope in terms of the velocity of flowing water is up to $15 \mathrm{~cm} / \mathrm{s}$ (fig. 6 b) - while in terms of set angles, respectively: angle of attack in the range of $-20-+45$ degrees, 
yaw angle in the range of $-20-+20$ degrees (fig . $6 \mathrm{c}$ ). Both, the flow velocity parameter, as well as relevant angles, are set by software. Changing the angle is possible every first degree in two axes.

The test chamber is equipped with two $8 \mathrm{~mm}$ thick widows, enabling observation of the phenomena undergoing inside. The tunnel was filled up to the top edge of the measuring chamber windows. A removable cover is mounted half-way through the basin, with its purpose being the arresting of waves formed on the surface and, with the help of a mesh, levelling the water stream flow [14].

A vane water pump with an appropriate flow sucks the water through two inlets located at the end of the tunnel. Vortex dissipaters are mounted above the inlets, to prevent sucking in air by the vortices formed in the water. The water sucked in through the inlets then flows through a tube with a diameter of $60 \mathrm{~mm}$, located under the panel for the water pump. The pump is driven by an AC motor with adjustable rotational speed. Together with the changing rotational speed of the pump, the water flow speed in the measuring chamber changes. A change of the water velocity in the chamber is a little delayed in relation to the change of the pump rotation speed, which results from the time needed to pump enough water to the main chamber. This delay is estimated to be approximately $10 \mathrm{~s}$ [14].

Water from the pump is directed to the labyrinth diffuser, designed to remove potential air bubbles. Next, the water flows above the top edge of the outer rim. The outflowing water is directed by the basin walls towards the measurement chamber. The opening of the basin narrows gradually, which causes the dispersion of the stream so that it reaches an appropriate flow velocity next to the measuring chamber [14].

\subsection{Airfoil design with flight control systems}

a)

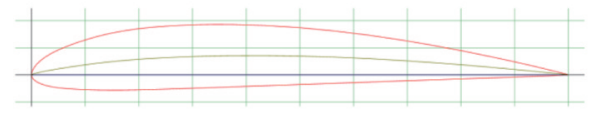

c)

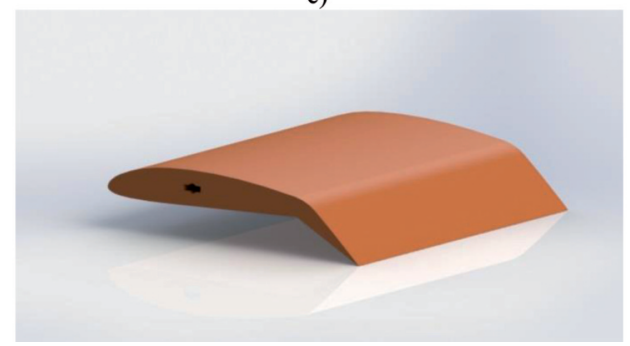

b)

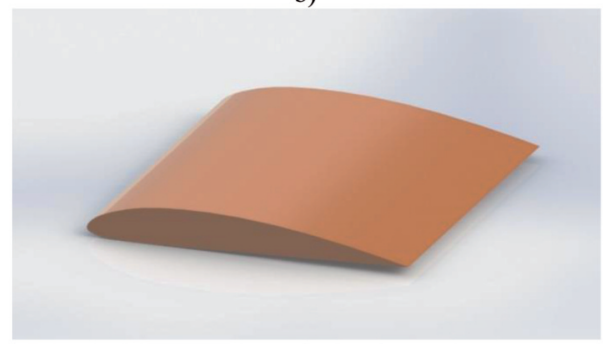

d)

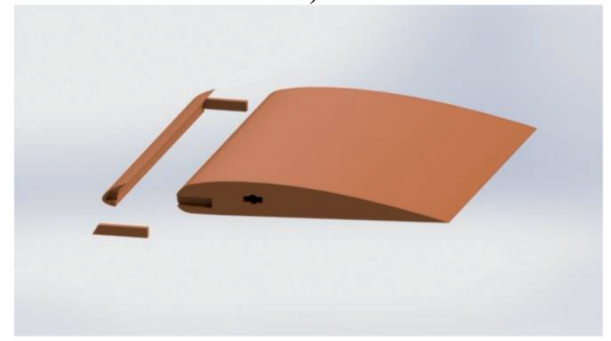

Fig. 7. A) Clark Y $11.7 \%$ airfoil [13]. View of an airfoil b) base, c) with a flap and d) with a slot [Filipiak, 2016]

Three models of Clark Y 11.7\% airfoil with flight control systems and a prototype of a dye feeder into to a water tunnel was utilised during tests. The Clark Y 11.7\% airfoil, commonly known in general and modelling aviation, was used as the base. It was created by Virginius E. Clark in 1922. An example of its practical application is aircraft of the pioneer of American aviation, Charles Lindbergh, the Spirit of St. Louis, which Lindbergh used to make the first in history flight from New York to Paris, without any stopovers in April 1928. The data of the airfoil were collected from 
a database of airfoils of the University of Illinois in Urbana-Champaign (UIUC Airfoils Coordinates Database) [13] in the form of a file in the .dat format, which included the coordinates of points forming the airfoil curve. The profile was recreated in Solidworks software.

The airfoil sketch was scaled to the dimensions depending from the size of the measuring chamber of the water tunnel, where the tests were conducted. Next, three models were created on its base (fig. 7):

- base airfoil

- airfoil with a flap

- airfoil with a slot.

An airfoil with a slot consists of three parts, the profile, slot and a connector. Printing an entire model as one part would cause problems with its skimming and painting.

All printed models were saved in the Solidworks software in STL file format. Since the modelled objects in most CAD software are described with NURBS surfaces, these objects have to be converted to grid geometry. Interpolation of the NURBS surfaces with a grid of triangles at a specified accuracy was performed afterwards (fig. 8). The files in the STL format contain the coordinates of vertices of flat triangular walls and the coordinates of their normal vectors. The grids of all models were created with the greatest accuracy allowed by the software, in order to provide an airfoil as similar to the baseline curve as possible.

The STL files were imported to the MakerBot Desktop software, which determined the print out parameters of individual objects. One of the parameters was the position and orientation of the printed object. All airfoils were laid "on the side". Such a position ensured the best airfoil curve print out quality.

The thickness of an individual print out layers was also determined in the software, and it was $0.1 \mathrm{~mm}$ for all of the models. The next parameter was the degree and type of filling. If there is no need to print a homogeneous solid, the filling used is a derivative of a given formula along the vertical axis. The density of the formula depends on the degree of filling stated in percentage. A ten-degree diamond filling was used for each printed object (fig. 8). The wall thickness in a model was defined by the amount of coating layer. A clean airfoil model was printed out as the first one and had only one coating layer used on it. As a result, the printed airfoil had shortcomings in the form of numerous holes near the leading edge. The layer number in subsequent models was increased to three, which solved this problem at the expense of increasing the printing time and used filament (PLA in the form of a thread wrapped on a spool).

a)

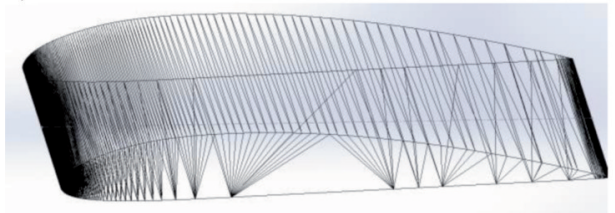

b)

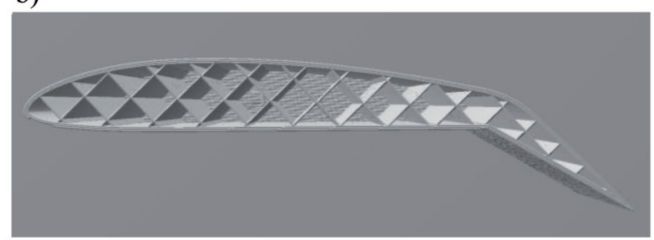

Fig. 8. a) Grid of triangles in a STL file for a clean airfoil, b) Preview of a print section of an airfoil with a flap. Visible structure of diamond fillin and three coating layers [Zahorski, 2016]

In order to enable fastening airfoils to a measuring head of the water tunnel, a holder in the form of a fork (fig. 9 a) was designed and printed, so individual airfoils could be installed in it. Because practical tests showed that holders without reinforcement were not rigid enough, reinforcement was introduced (reinforced through the use of a metal wire) (fig. 9b). 
a)

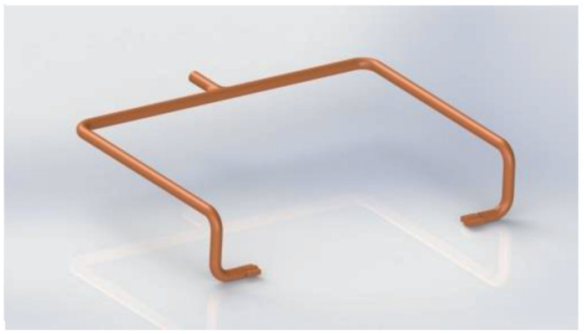

b)

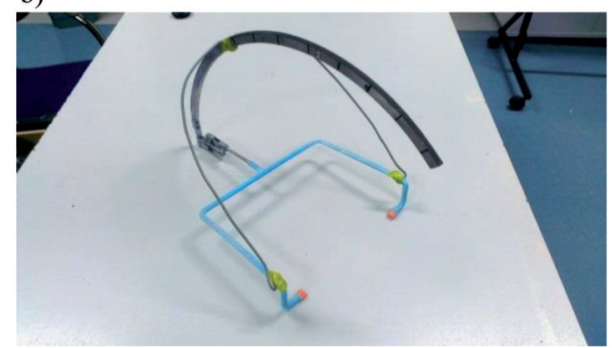

Fig. 9 a) View of a printed out holder and b) Holder fastened to a measuring head with reinforcement [Filipiak, 2016]

\subsection{Preparation of models for experimental tests}

After being printed, each of the models had a texture, which is specific for object printed out in the FDM technology. In order to eliminate all surface unevenness, each of the models was coated with putty (fig. 10). After applying and smoothing the putty, each model was carefully ground and cleaned with sandpaper, in order to achieve as smooth a surface as possible.

In order to protect the models against potential, undesired effect caused by the impact of water, they were painted with waterproof epoxy varnish (fig. 10.b). White varnish colour was selected due to the fact that it best suits models intended for the flow visualisation in a water tunnel with the use of a dye.
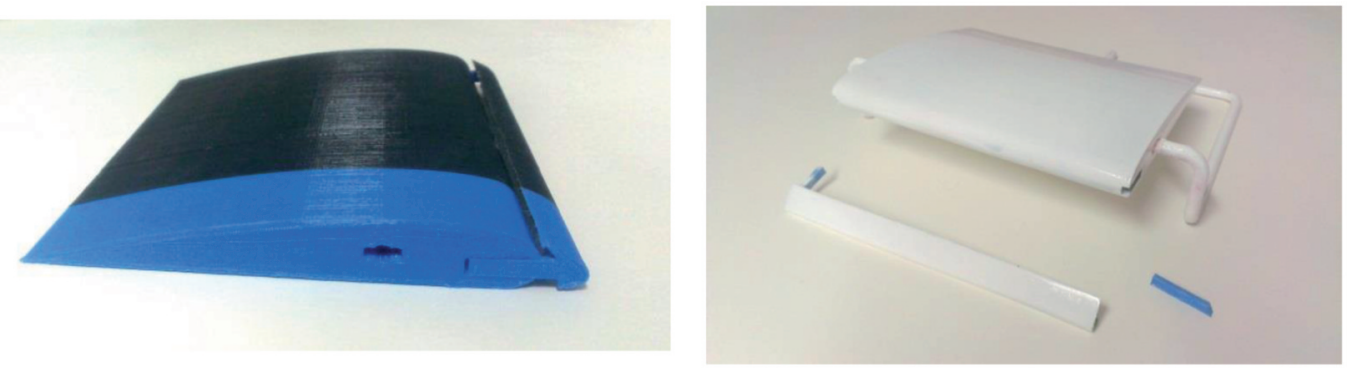

Fig. 10. a) Airfoil model with a slot directly, after printing. The model is two-colour due to a change in the filament, forced by the previous one running out, b) Airfoil model with a slot, after varnishing [Filipiak, 2016].

\subsection{Preparation of the dye feeder}

A long, aluminium tube $5 \mathrm{~mm}$ in diameter was placed in the tunnel and connected with a dye feed, for the purposes of supplying a dye stream in front of the models. It was drilled from the inside in the outlet part, in order to decrease wall thickness and minimize disruptions formed when mixing the dye with water.

At low flow rate, the dye formed a slightly disrupted stream, gradually blurring along with the increasing distance from the tube outlet. Increasing the flow rate resulted in thickening of the stream. At a greater mass flow rate, gravitational settling of the dye caused by its density, greater than water density, was observed (fig. 11). 

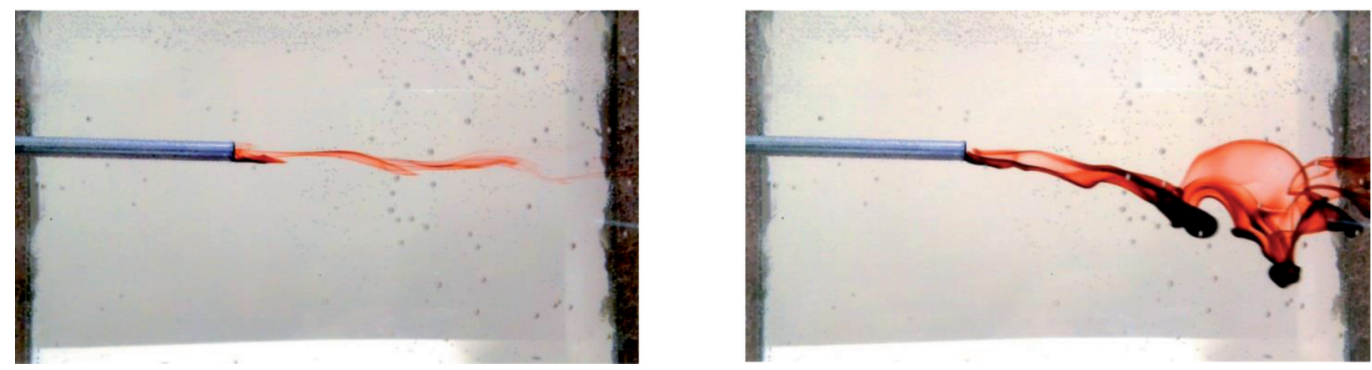

Fig. 11. a) Dye stream from a tube at low flow rate, b) Dye stream from a tube at medium flow rate. Visible dye settling [Filipiak, 2016]

\subsection{Tunnel test}

Due to carrying out only visualisation tests, the aerodynamic characteristics of the Clark Y airfoil (fig. 12) are based on the literature [15] and have marked values of the angles of attack, which were used in the visualisation. Angles, for which the simulation was conducted, are marked with "W". Each of the airfoils was subsequently placed in a water tunnel and observed. The base airfoil and the one with a slot were set in four positions, corresponding the following angles of attack: $-5^{\circ}, 0^{\circ}, 10^{\circ}$, $20^{\circ}$. An airfoil with a flap was tested for the following angles of attack: $0^{\circ}, 10^{\circ}, 20^{\circ}$. Such sizes of the angles of attack were selected due to the scope of application of individual flight control systems when manoeuvring. Flow field around the models was observed at each of the mentioned positions for two water velocities: $4 \mathrm{~cm} / \mathrm{s}$ and $8 \mathrm{~cm} / \mathrm{s}$.

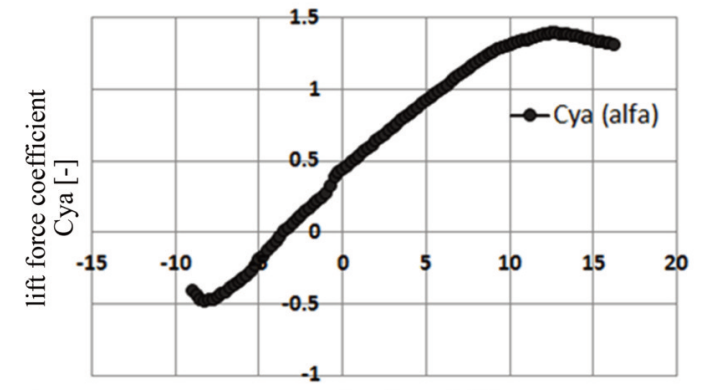

a)

angle of attack $\left[^{\circ}\right]$

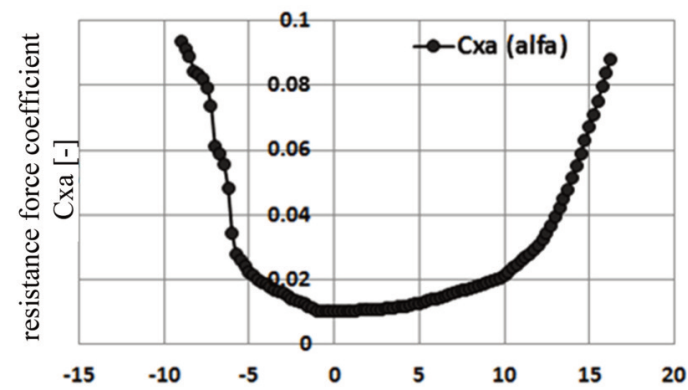

b)

Fig. 12. Aerodynamic characteristics of a Clark Y airfoil a) lift force coefficient vs angle of attack b) resistance force coefficient vs the angle of attack [14]

\section{$\underline{\text { 4.5.1. Angle of attack }-5^{\circ}}$}

For a negative angle of attack, the flow around the airfoil in the base configuration and one with a slot was similar. Laminar flow appeared along the entire length of both airfoils, while slight disturbances of the fluid streams appeared beyond the airfoils. The nature of the flow is similar at both velocities (fig. 13). We can also observe slight dye settling due to its density, which negatively affects the degree of illustrating of the actual motion of water streams. 

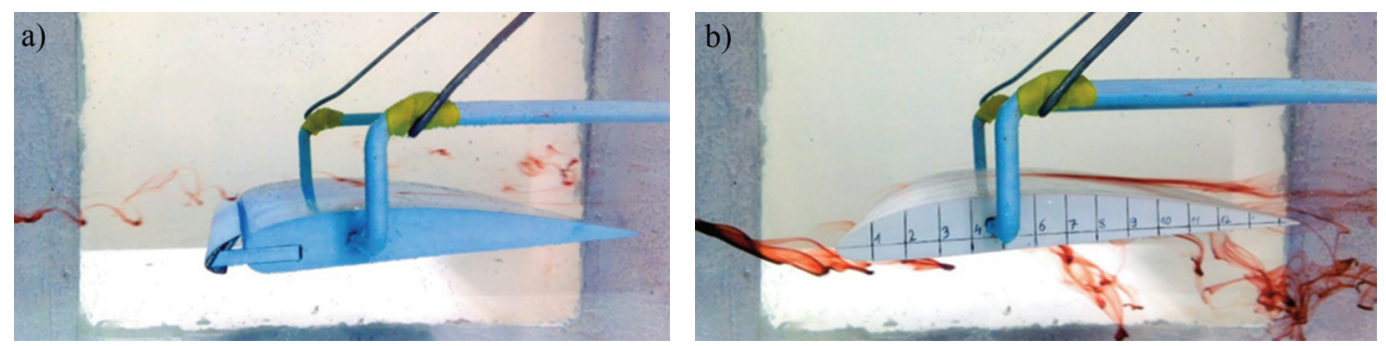

Fig. 13 a) Flow around a slotted airfoil and b) base airfoil, angle of attack $-5^{\circ}, v=8 \mathrm{~m} / \mathrm{s}$ [Filipiak, 2016]

\subsubsection{Angle of attack $0^{\circ}$}

At a zero angle of attack on a clean airfoil, a zone with reversed flow could be seen, occurring in the rear part of an airfoil and for $8 \mathrm{~cm} / \mathrm{s}$ being lower than for $4 \mathrm{~cm} / \mathrm{s}$. Flow separation can be seen behind the airfoil.
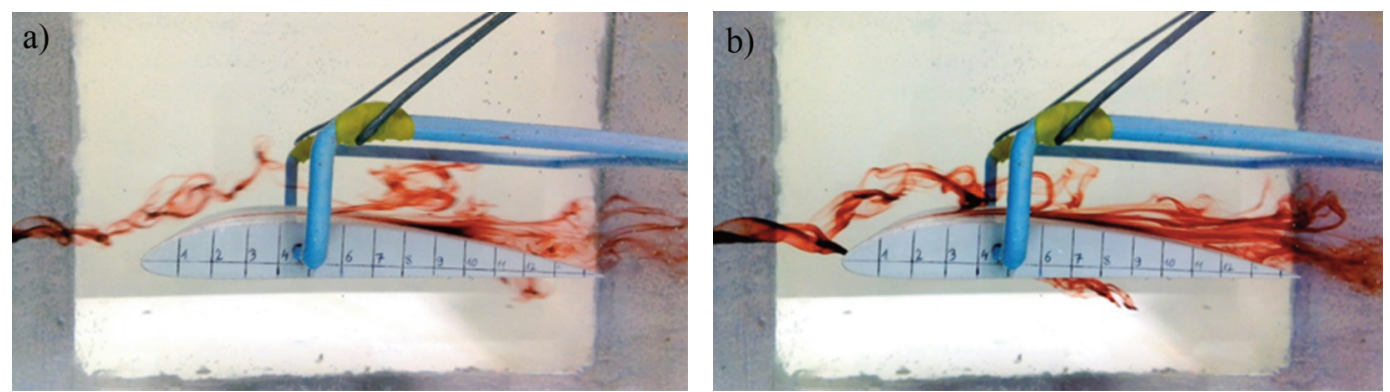

Fig. 14. Clean airfoil, angle of attack $\alpha=0^{\circ}$, flow velocity: a) $\left.v=8 \mathrm{~cm} / \mathrm{s}, \mathrm{b}\right) \mathrm{v}=4 \mathrm{~cm} / \mathrm{s}$ [Filipiak, 2016]

Flow separation behind the flap were noticed when testing an airfoil with a flap (fig. 15). The streams of water with a dye in this zone were subjected to strong turbulence. The nature of the flow is similar for both velocities.
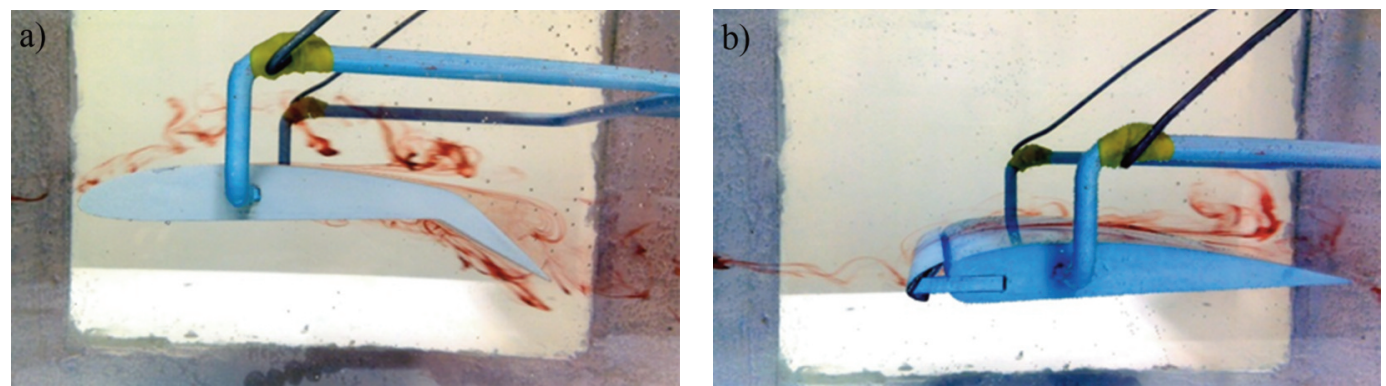

Fig. 15 a) An airfoil with a flap and b) slotted, angle of attack $\alpha=0^{\circ}, \mathrm{v}=8 \mathrm{~cm} / \mathrm{s}$ [Filipiak, 2016]

In the case of an airfoil with a slot, the nature of the flow is similar to the base airfoil. A zone of significantly slower flow can be seen (laminar zone) Sucking in of the stream from over the airfoil into the slot was seen. 


\subsubsection{Angle of attack $10^{\circ}$}

A distinct difference between a clean airfoil and one with a slot can be seen at an angle of attack $\alpha=10^{\circ}$ (fig. 16). In the case of a clean airfoil, the zone of disturbed flow begins around $2-3 \mathrm{~cm}$ from the airfoil tip, while in the case of one with a slot, it increases by a further $2-3 \mathrm{~cm}$. A correct operation of the slot was also observed with the stream of fluid flowing from under the airfoil being sucked into it.
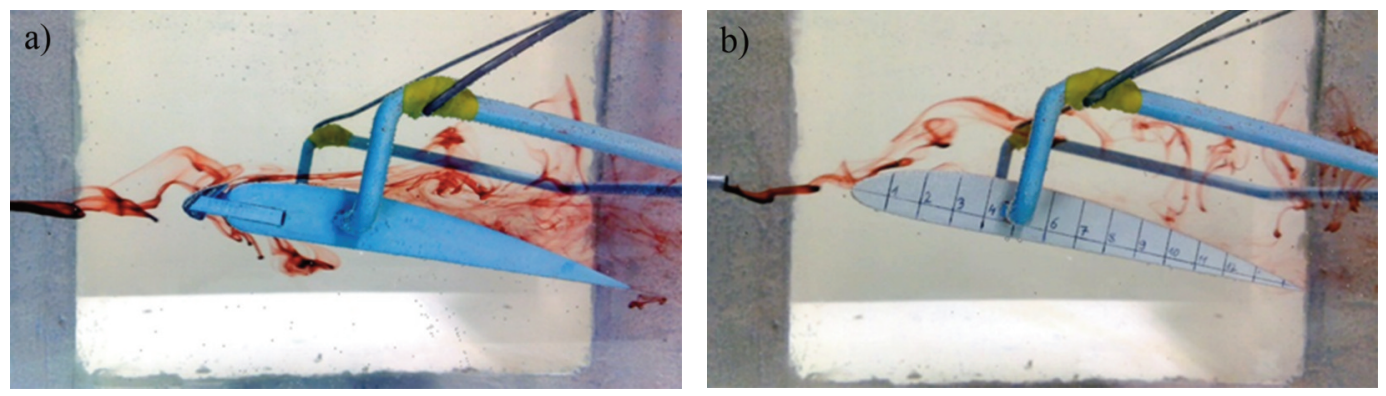

Fig. 16 a) An airfoil with a slot and b) base airfoil, angle of attack $\alpha=10^{\circ}, \mathrm{v}=4 \mathrm{~cm} / \mathrm{s}$ [Filipiak, 2016]
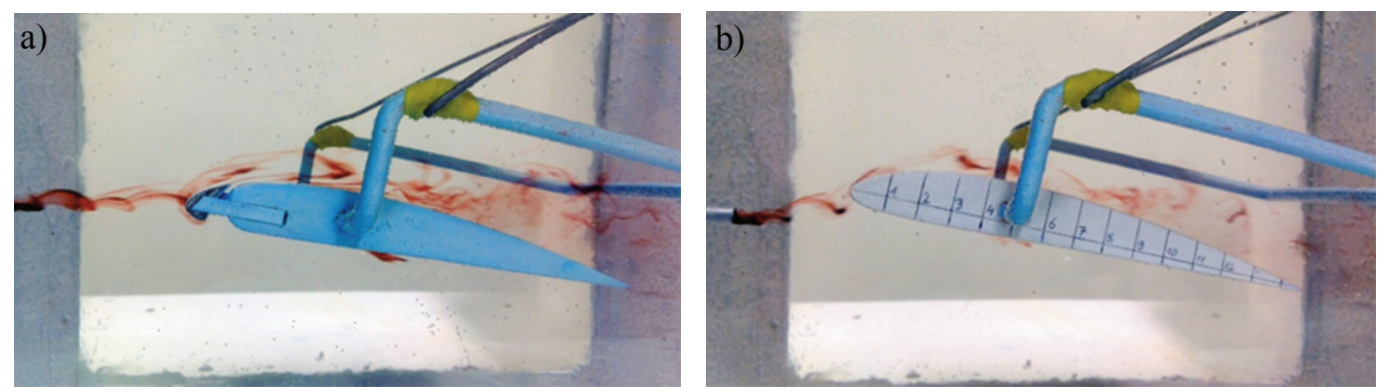

Fig. 17 a) An airfoil with a slot and b) base airfoil, angle of attack $\alpha=10^{\circ}, v=8 \mathrm{~cm} / \mathrm{s}$ [Filipiak, 2016]

Flow around an airfoil with a flap was shown in fig. 18, and, similarly to the case of a clean airfoil, strong turbulence on the edge of the streamline could be noted, but, the zone of the laminar layer along the top contour significantly expanded.

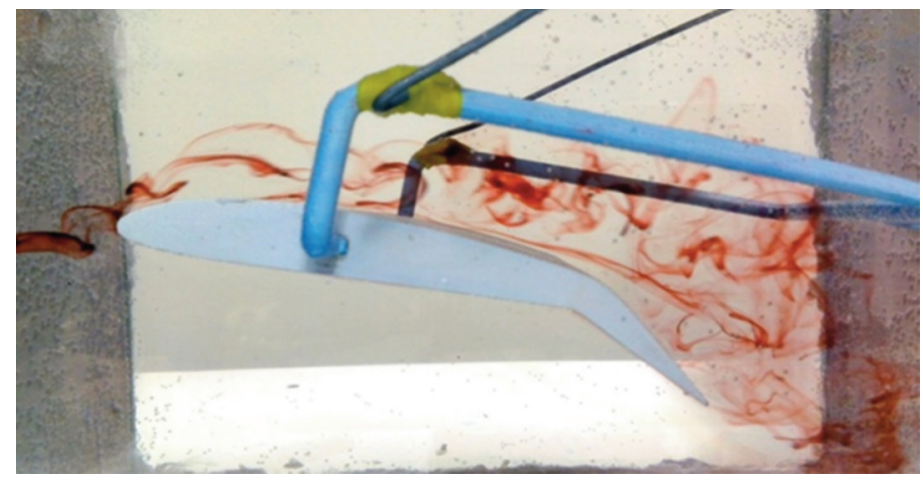

Fig. 18. An airfoil with a flap, angle of attack $\alpha=10^{\circ}$, flow velocity $\mathrm{v}=4 \mathrm{~cm} / \mathrm{s}$ [Filipiak, 2016] 


\subsubsection{Angle of attack $20^{\circ}$}

For an angle of attack of $20^{\circ}$ and in the case of a clean profile and one with a slot, fig. 19 present the observed phenomena, which were similar to these for $\alpha=10^{\circ}$. The flow is strongly disturbed above all airfoils, especially at $8 \mathrm{~cm} / \mathrm{s}$. In addition, strong influence of the slot on the nature of the flow in the initial airfoil streamline zone can be seen.
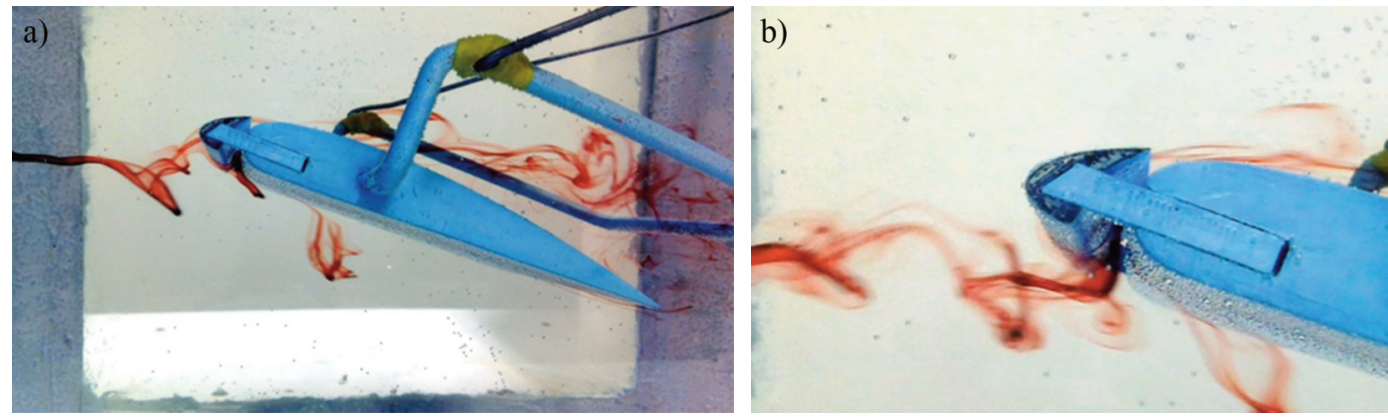

Fig. 19 a) An airfoil with a slot, angle of attack $\alpha=20^{\circ}$, flow velocity $\mathrm{v}=4 \mathrm{~cm} / \mathrm{s}$ and b) slot enlarged [Filipiak, 2016] Very clearly visible sucking in of the stream into the slot gap. [Filipiak, 2016]

With such large angles of attack, the flows are highly disturbed. This could be expected after the interpretations of aerodynamic characteristics (fig. 12).
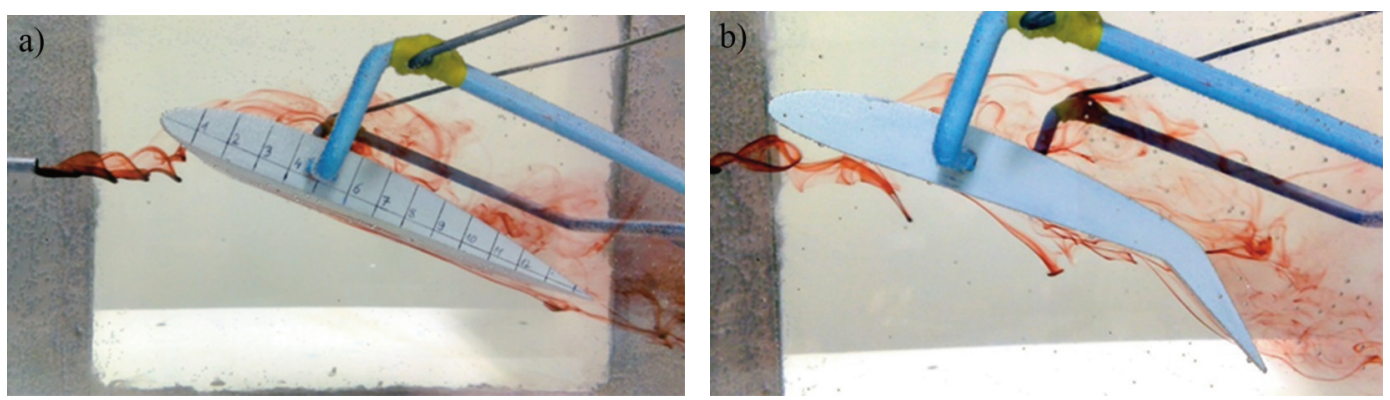

Fig. 20 a) Base airfoil and b) with a flap, angle of attack $\alpha=20^{\circ}$, flow velocity $\mathrm{v}=4 \mathrm{~cm} / \mathrm{s}$ [Filipiak, 2016]

\section{CONCLUSIONS}

The presented results of the flow visualisation for wing models (Clark $Y$ airfoil) with flight control systems are reliable and very useful in terms of quality and for describing the phenomena by using flaps and slots. The conducted studies helped to identify problems and benefits of using dyes in a water tunnel. Most certainly, it can be concluded that flow visualisation is a method, which is useful in the process of identifying a certain type of phenomena occurring during aerodynamic tests, in aviation in particular. However, in order to fully exploit the potential of this technique, the system feeding the dye directly on the model or in immediate vicinity of sensitive and tested areas of the streamlined element can be improved and made more effective. However, it is associated with problems in terms of manufacturing technology for models of such a type. Furthermore, the flow disturbance caused by the device itself in case of feeding the dye in front of the model should be carefully considered. 
In the course of development this paper, the legitimacy of using 3D printing technology and CAD software in preparing of models for tests in water tunnels was confirmed. It is a relatively cheap and effective method, which allows to create complex objects with high accuracy and repeatability.

\section{BIBLIOGRAPHY}

[1] Erickson, G.E., Peake, D.J., Del Frate, J., Skow, A.M., Malcolm, G.N., 1987, "Water Facilities in Retrospect and Prospect -an Illuminating Tool for Vehicle Design” Tech. Memo. 89409, National Aeronautics and Space Administration.

[2] von Karman. T., 1954, Aerodynamics, McGraw-Hill Book Company, Nowy Jork

[3] Lugt, H. J., 1983, Vortex Flows in Nature and Technology, John Wiley \& Sons, Nowy Jork

[4] Reynolds, O., 1883, “An Experimental Investigation of the Circumstances Which Determine Whether the Motion of Water Shall Be Direct or Sinuous, and of the Law of Resistance in Parallel Channels", Philosophical Transactions of the Royal Society of London, 174, s. 935-982.

[5] Eckert, M., 2006, The Dawn of Fluid Dynamics: A Discipline Between Science and Technology, John Wiley \& Sons, Weinheim

[6] Prandtl, L., Tietjens, O.G., 1934, “Applied Hydro- and Aeromechanics”, Dover Publications, Nowy Jork

[7] Hoerner, S. F., 1965, Fluid Dynamic Drag, Bricktown, New Jersey

[8] Del Frate, J.H., 1995, "NASA Dryden Flow Visualization Facility”, Technical Memorandum 4631, National Aeronautics and Space Administration

[9] Jakubowski, M., Sterczyńska, Dresner, J., 2013, „Bezkontaktowa technika pomiaru PIV. Analiza przepływów w urządzeniach przemysłu spożywczego" [Non-contact PIV measuring technology. Flow analysis in food industry devices”, Przemysł Spożywczy, 67, s. 22-25.

[10] Stryczniewicz, W., 2012, „Algorytm do wyznaczania wektorowego pola prędkości metodą anemometrii obrazowej" [An algorithm for the determination of a vector velocity field with the PIV method], Problemy Mechatroniki, 9, s. 41-54.

[11] Merlo, N., Boushaki, T., Chauveau, C., de Persis, S., Pillier, L., Sarh, B., Gökalp, I.. 2013, "Experimental Study of Oxygen Enrichment Effects on Turbulent Non-premixed Swirling Flames", Energy Fuels, 27, s. 6191-6197

[12] „TSI”, http://tsi.com

[13] „UIUC Applied Aerodynamics Group”, http://m-selig.ae.illinois.edu/ads/coord database.html

[14] „Tunel hydrodynamiczny (prototyp)”, dokumentacja techniczna TUN/2011, Projekt 122, ELBIT Firma innowacyjno - wdrożeniowa [A hydrodynamic tunnel (prototype). Technical documentation TUN/2011, Project 122, ELBIT - An innovations-implementation company], 2011

[15] „Airfoil tools”, http://airfoiltools.com/airfoil/details?airfoil=clarky-il 


\section{WIZUALIZACJA PRZEPLYWU WOKÓŁ MODELU SKRZYDLA Z MECHANIZACJĄ W TUNELU WODNYM}

\section{Streszczenie}

W pracy przedstawiono uzasadnienie możliwości zastosowania tunelu wodnego do wizualizacji przepływu modeli profili lotniczych z mechanizacją w postaci slotów i klap. Ponadto przybliżono tematykę zastosowania tuneli wodnych w celach naukowych jak i szkoleniowych. Przedstawiono również technologię wydruku 3D modeli do testów praktycznych w tunelu wodnym. Eksperyment obejmował przeprowadzenie badań wizualizacyjnych dla trzech modeli profilu lotniczego: jako bazowy profil Clark Y $11.7 \%$ oraz ten sam profil ze slotem i z klapą. Ponadto autorzy pracy wprowadzili modyfikację wprowadzania barwnika przed badany model geometryczny umiejscowiony na trzymaku w przestrzeni pomiarowej. Przedstawione wyniki zobrazowania przepływu wokół modeli za pomocą barwnika potwierdziły skuteczność zastosowanej metodyki prowadzenia eksperymentu na charakterystycznych kątach natarcia. Wyniki i wnioski można wykorzystać do zweryfikowania większości zagadnień przepływowych w tunelach hydrodynamicznych jak również mogą posłużyć jako element szkoleniowy.

Słowa kluczowe: badania w tunelu wodnym, profil lotniczy, klapy, sloty. 